\title{
The Functional Characterization of Long Noncoding RNA SPRY4- IT1 in Human Melanoma Cells
}

\author{
Joseph Mazar ${ }^{1}$, Wei Zhao', Ahmad M. Khalil'², Bongyong Lee ${ }^{1}$, John Shelley ${ }^{1}$, \\ Subramaniam S. Govindarajan ${ }^{1}$, Fumiko Yamamoto ${ }^{1}$, Maya Ratnam², Muhammad \\ Nauman Aftab ${ }^{1}$, Sheila Collins ${ }^{1}$, Brian N. Finck ${ }^{3}$, Xianlin Han ${ }^{1}$, John S. Mattick ${ }^{4}$, \\ Marcel E. Dinger ${ }^{4}$, and Ranjan J. Perera ${ }^{1 *}$ \\ 1 Sanford-Burnham Medical Research Institute, Orlando, FL 32827, USA \\ 2 Department of Genetics and Genome Sciences, Case Western Reserve University School of Medicine, Cleveland, OH 44106, \\ USA \\ ${ }^{3}$ Division of Geriatrics and Nutritional Sciences, Washington University School of Medicine, St. Louis, MO 63110, USA \\ ${ }^{4}$ Garvan Institute of Medical Research and St Vincent's Clinical School, University of New South Wales, Darlinghurst NSW \\ 2010, Australia
}

Correspondence to: Ranjan J. Perera, email: rperera@sanfordburnham.org

Keywords: long noncoding RNA, melanoma

Received: January 23, $2014 \quad$ Accepted: March $242014 \quad$ Published: March 26, 2014

This is an open-access article distributed under the terms of the Creative Commons Attribution License, which permits unrestricted use, distribution, and reproduction in any medium, provided the original author and source are credited.

\section{ABSTRACT:}

Expression of the long noncoding RNA (IncRNA) SPRY4-IT1 is low in normal human melanocytes but high in melanoma cells. siRNA knockdown of SPRY4IT1 blocks melanoma cell invasion and proliferation, and increases apoptosis. To investigate its function further, we affinity purified SPRY4-IT1 from melanoma cells and used mass spectrometry to identify the protein lipin 2, an enzyme that converts phosphatidate to diacylglycerol (DAG), as a major binding partner. SPRY4IT1 knockdown increases the accumulation of lipin 2 protein and upregulate the expression of diacylglycerol 0-acyltransferase 2 (DGAT2) an enzyme involved in the conversion of DAG to triacylglycerol (TAG). When SPRY4-IT1 knockdown and control melanoma cells were subjected to shotgun lipidomics, an MS-based assay that permits the quantification of changes in the cellular lipid profile, we found that SPRY4IT1 knockdown induced significant changes in a number of lipid species, including increased acyl carnitine, fatty acyl chains, and triacylglycerol (TAG). Together, these results suggest the possibility that SPRY4-IT1 knockdown may induce apoptosis via lipin 2-mediated alterations in lipid metabolism leading to cellular lipotoxicity.

\section{INTRODUCTION}

Eukaryotic genomes express a complex repertoire of thousands of RNAs that lack protein-coding capacity $[1,2]$. These noncoding RNAs (ncRNAs) are broadly classified as long or small based on a nucleotide length of $>200$ or $<200$ nucleotides (nt), respectively. Small regulatory ncRNAs are commonly conserved and are involved in transcriptional and posttranscriptional gene regulation through specific base pairing with their target genes or transcripts. In contrast, long noncoding RNAs (lncRNAs) are less well conserved and regulate gene expression by diverse mechanisms, including epigenetic mechanisms, that remain incompletely understood [3-6].
LncRNAs may be derived from genomic sequences that are intergenic, intronic, overlapping, or antisense with respect to nearby protein-coding genes, and although some IncRNAs may be translated into short polypeptides, the vast majority are rarely or never translated [7, 8].

Until recently, lncRNAs were frequently dismissed as non-functional transcriptional "noise" [9]. However, the past few years have seen a rapid increase in our understanding of the regulatory functions of $\operatorname{lncRNAs}$ and their role in human disease and development [10, 11]. LncRNAs exhibit exquisite context-dependency commensurate with their presumed regulatory role, with cell type-specific expression and localization to discrete subcellular compartments [12-14]. At the molecular level, 
lncRNAs influence target gene expression at specific genomic loci by directly interacting with chromatin regulatory proteins and/or by modulating the activity of their interacting partners [15-20]. LncRNAs can function as decoys for bound proteins and can also alter the structure and function of the protein [17]. Although lncRNAs play physiological roles during normal cellular development and differentiation [21], changes in their expression are associated with several diseases, including cancer, heart disease, Alzheimer's disease, psoriasis, and spinocerebellar ataxia type 8 [22]. Accumulating evidence suggests that lncRNAs may also play a role in tumorigenesis. For example, increased expression of HOTAIR is associated with poor prognosis in pancreatic cancer [23], and increased expression of PCGEM1 and $P C A 3 / D D 3$ is associated with a high risk of developing prostate cancer [24].

Recently, we identified a number of IncRNAs that are differentially expressed in melanoma cell lines relative to melanocytes and keratinocytes [14, 25]. One of these, SPRY4-IT1 (Sprouty4-Intron 1; GenBank accession ID AK024556), is highly expressed in melanoma cells relative to melanocytes, and is localized predominantly in the cytoplasm. Previously we showed that SPRY4-IT1 is derived from the intronic region of the SPRY4 gene and that its predicted secondary structure contains several long hairpins [14]. Moreover, RNAi-mediated knockdown of SPRY4-IT1 inhibited invasion and proliferation and induced apoptosis of melanoma cells, suggesting an important role for this lncRNA in melanoma biology.

In the present study, we sought to identify SPRY4IT1-interacting proteins and elucidate this lncRNA's molecular function. In melanoma cells, SPRY4-IT1 transcripts are processed in the nucleus prior to transport to the cytoplasm, where they are primarily located in polysomes. We also identify the phosphatidate lipin 2 as a major SPRY4-IT1-binding protein, and demonstrate the existence of a novel lipid regulatory mechanism involving SPRY4-IT1 and lipin 2. Our results are consistent with the possibility that SPRY4-IT1 knockdown may induce apoptosis via lipin 2-mediated alterations in lipid metabolism leading to cellular lipotoxicity. Together these results provide novel insight into the mechanisms by which extranuclear processing of lncRNAs contributes to melanoma biology.

\section{RESULTS}

\section{Processing of SPRY4-IT1 Transcripts}

SPRY4-IT1 was originally identified as a 706 bp transcript in adipose tissue as part of a large-scale cDNA sequencing study [26]. The SPRY4-IT1 sequence was shown by PCR to initiate in intron 1 of the SPRY4 gene and extend to exon 3 (Fig. 1A). Interestingly, the 5' region of the full-length SPRY4-IT1 transcript was detected in samples of nuclear, but not cytoplasmic RNA, suggesting that the processing of SPRY4-IT1 takes place before nucleocytoplasmic export (Fig. 1B). We confirmed using 5' RACE that the first 244 nt of the 5' sequence is missing from cytoplasmic SPRY4-IT1 (Fig. S1). To validate this observation and to visualize the subcellular localization of SPRY4-IT1, we designed several RNA-FISH probes specific for the 3' or 5' regions of SPRY4-IT1. This analysis confirmed the presence of the full-length transcript in the nucleus but not in the cytoplasm (Fig. S2), in agreement with PCR results. SPRY4-IT1 staining in melanocytes is mainly localized to the nucleus and this may be the reason of intense nuclear staining in melanocytes. Together these data demonstrate that the SPRY4-IT1 transcript undergoes maturation by cleavage of the 5 ' region prior to its transport to the cytoplasm. This may suggest that the regulation of the 5' cleavage controls the export of the transcript to the cytoplasm thus, the overall SPRY4IT1 content may depend on the efficiency of the nuclear excision event.

Although the precise $3^{\prime}$ termination site of the SPRY4-IT1 transcript is not yet known, northern blot analysis shows a SPRY4-IT1 transcript size of approximately $1.8 \mathrm{~kb}$ (Fig. 1C), and the $3^{\prime}$ sequence of the transcript is very similar to that of Exon 3 of the SPRY4 gene. Therefore, we propose that SPRY4-IT1 carries both intronic and exonic sequences and can be considered a noncoding splice variant of the SPRY4 gene.

\section{SPRY4-IT1 and SPRY4 Gene Transcripts Function Independently}

We next asked whether the transcription and function of SPRY4-IT1 and SPRY4 are coordinately or independently regulated. Despite the similar expression patterns of SPRY4 and SPRY4-IT1, siRNA-mediated knockdown of SPRY4 (siRNA targeting exon 1) in A375 melanoma cells reduced the expression of SPRY4 but not SPRY4-IT1 (Fig. 1D), demonstrating that transcription of the coding (SPRY4) and noncoding (SPRY4-IT1) genes occurred independently. To confirm this in a more physiological setting, we treated melanocytes (low expression of SPRY4-IT1) with fibroblast growth factor 2 (FGF2), which is known to induce SPRY4 expression [27]. In serum-containing medium, FGF2 induced expression of SPRY4-IT1 and SPRY4 to similar extents (Fig. 2A). However, SPRY4-IT1 transcription was further elevated in melanocytes treated with FGF2 in serum-free medium (Fig. 2B), confirming independent transcription of SPRY4IT1 and SPRY4. These results suggest that SPRY4-IT1 responds to starvation and general stress responses.

To determine whether the stability of SPRY4-IT1 and $S P R Y 4$ transcripts is independently regulated, we treated 

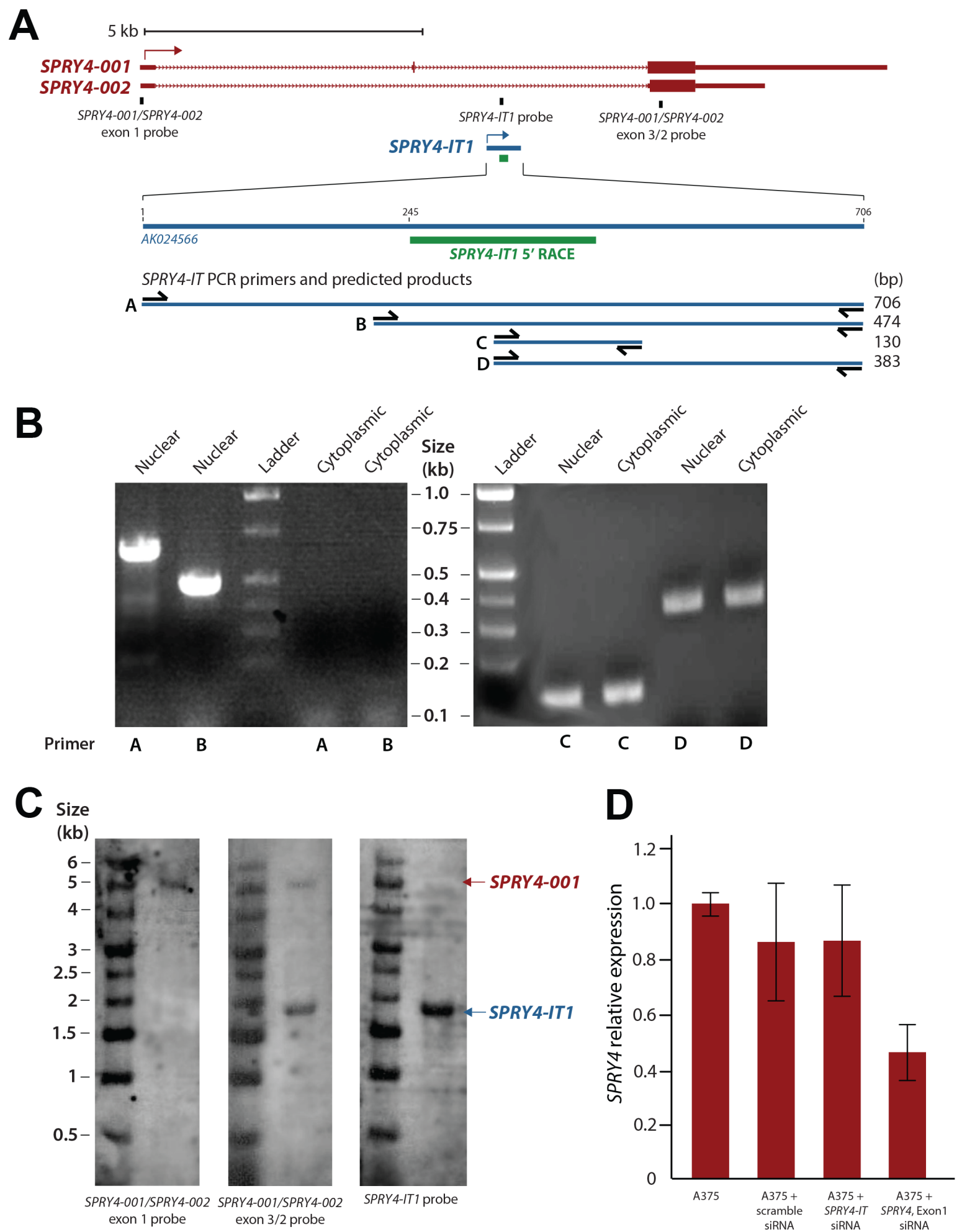

Figure 1:Maturation and Cellular Compartmentalization of SPRY4-IT1 Transcripts. (A) The sequence and location of SPRY4 and SPRY4-IT1. SPRY4-ITI is embedded in the SPRY4 parent transcript. SPRY4-IT1 starts in the first intron of the SPRY4 gene and extends up to exon 3. 5' RACE shows the maturation and cleavage of a $244 \mathrm{nt}$ transcript in the $5^{\prime}$ region of SPRY4-ITI. (B) Detection of nuclear and cytoplasmic forms of SPRY4-ITI. (C) Northern blot analysis shows the sizes of SPRY4 (4.9 kb) and SPRY4-IT1 (1.8 kb). The $S P R Y 4$ exon 1 probe hybridizes specifically to SPRY4, but the SPRY4 exon 3 probes recognize both SPRY4 and SPRY4-IT. (D) SPRY4 exon 1 siRNA knocks down the expression of SPRY4, but not SPRY4-ITI, in A375 melanoma cells. 
A375 cells with the polymerase II transcriptional inhibitor $\alpha$-amanitin and measured the transcript levels by RTPCR. We observed that SPRY4 RNA decayed faster than SPRY4-IT1 in both the nucleus and cytoplasm, supporting the functional independence of the transcripts (Fig. S3). Finally, we independently knocked down SPRY4 and SPRY4-IT1 in A375 cells using transcript-specific siRNAs. Confirming our previous report [14], A375 cell invasion was inhibited $\sim 50 \%$ by SPRY4-IT1 knockdown but was unaffected by SPRY4 silencing (Fig. S4A). Similarly, SPRY4-IT1 silencing induced apoptosis of A375, as measured by caspase 3 activity, more effectively than did SPRY4 knockdown (Fig. S4B). Collectively, these data establish the transcriptional and functional independence of SPRY4-IT1 and its host gene SPRY4.

\section{SPRY4-IT1 Is Localized to the Polysome Fraction and Binds the Lipid Phosphatase Lipin 2}

In a recent ribosomal footprint study, Ingolia et al. [28] reported that cytoplasmic lncRNAs are primarily found in ribosomal clusters or polysomes. To determine the location of SPRY4-IT1, we used density gradient centrifugation to isolate monosomal and polysomal fractions from A375 cells and recovered 13 fractions: 2 monosomal and 11 polysomal (Fig. 3A). Total RNA was isolated from the individual fractions and analyzed for the presence of SPRY4-IT1 by northern blotting. SPRY4-IT1 was detected only in polysomal fractions 3 through 9 (Fig. 3B), indicating that SPRY4-IT1 is indeed associated with polysomes and is not retained in monosomes, consistent with the findings of Ingolia et al. [28]. Sequence analysis further confirmed that SPRY4-IT1

\section{A}

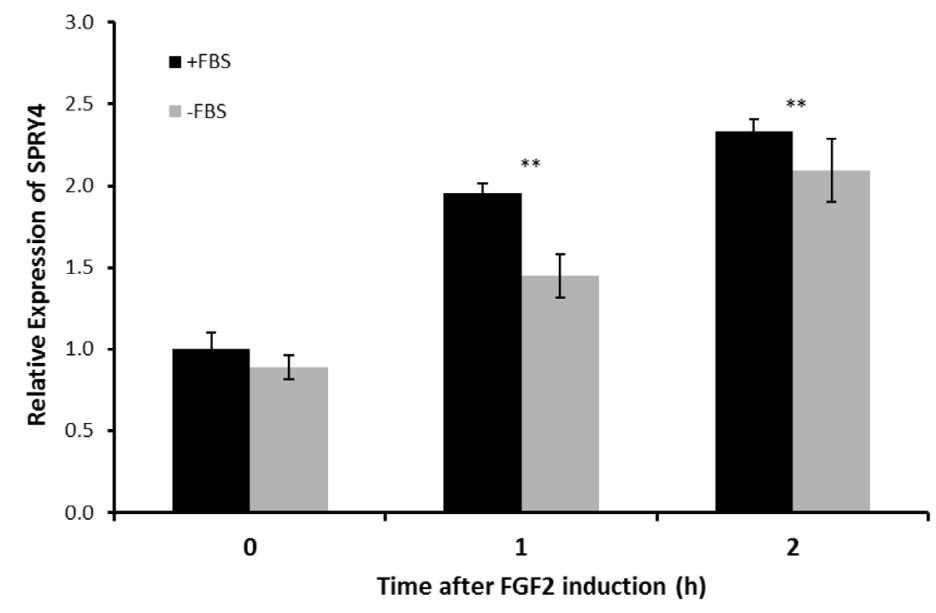

B

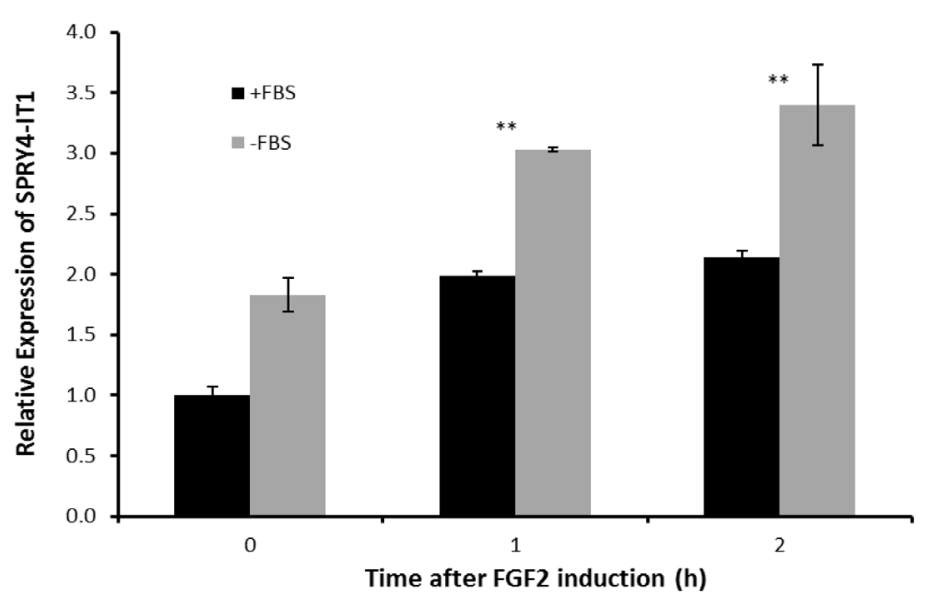

Figure 2: SPRY4 and SPRY4-IT1 Are Coordinately Regulated in Melanocytes. Relative expression of SPRY4-IT1 and SPRY4 following induction by FGF2. Melanocytes were treated with $10 \mathrm{ng} / \mathrm{ml} \mathrm{FGF2}$ for 1 or $2 \mathrm{~h}$ in the presence or absence of FBS, and the fold change in expression of SPRY4 (A) and SPRY4-IT1 (B) was measured by qPCR 
does not show any coding potential; understanding its role in possible translational regulation is an ongoing study in our laboratory.

We next sought to identify SPRY4-IT1-binding proteins in melanoma cells. For this, we affinity purified endogenous SPRY4-IT1 from crosslinked A375 lysate (Fig. 4A) and interrogated the SPRY4-IT1-associated proteins by mass spectrometry (MS). A group of candidate proteins was identified and quantified by spectral counting (Table S1). The most abundant protein candidate was lipin 2 [29], a phosphatidic acid phosphatase (PAP) that converts phosphatidate into diacylglycerol (DAG). Lipin 2 was pulled down specifically with SPRY4-IT1 but not with scrambled (control) probes. To verify the physical association between lipin 2 and SPRY4-IT1, lipin 2 was immunoprecipitated, and associated RNAs were isolated and interrogated for the presence of SPRY4-IT1 by qPCR. As shown in Figure 4B, SPRY4-IT1 transcripts were enriched in anti-lipin 2 immunoprecipitated compared with control IgG.

We next investigated the functional significance of the association between SPRY4-IT1 and lipin 2 in melanoma cells using gene-specific RNAi. Knockdown of lipin 2 with two independent siRNAs led to a concurrent loss of SPRY4-IT1 (Fig. 4C). This result suggests that the loss of lipin 2 most likely destabilizes SPRY4-IT1. In contrast, knockdown of SPRY4-IT1 increased both lipin 2 mRNA and protein by $\sim 2.5$-fold (Fig. 4D and 4F). PAP enzymatic activity was markedly increased in SPRY4IT1 knockdown cells (Fig. 4E). Given that SPRY4-IT1 knockdown had no effect on lipin 1 expression (Fig. S5), these data suggest that the increased PAP activity in these cells is due to the increased abundance of lipin 2. It is worth noting that knockdown of the SPRY4 gene did not affect the expression of either SPRY4-IT1 or lipin 2 (Fig. 4).

\section{SPRY4-IT1 Knockdown Increases Triacylglycerol Production via Lipin 2}

To investigate the effect of SPRY4-IT1 modulation of lipin 2 expression on global lipid metabolism in melanoma cells, we subjected SPRY4-IT1 knockdown and control A375 cells to shotgun lipidomics, an MS-based assay that permits the quantification of changes in the cellular lipid profile (Table S2). We found that SPRY4-IT1 knockdown induced significant changes in a number of lipid species,

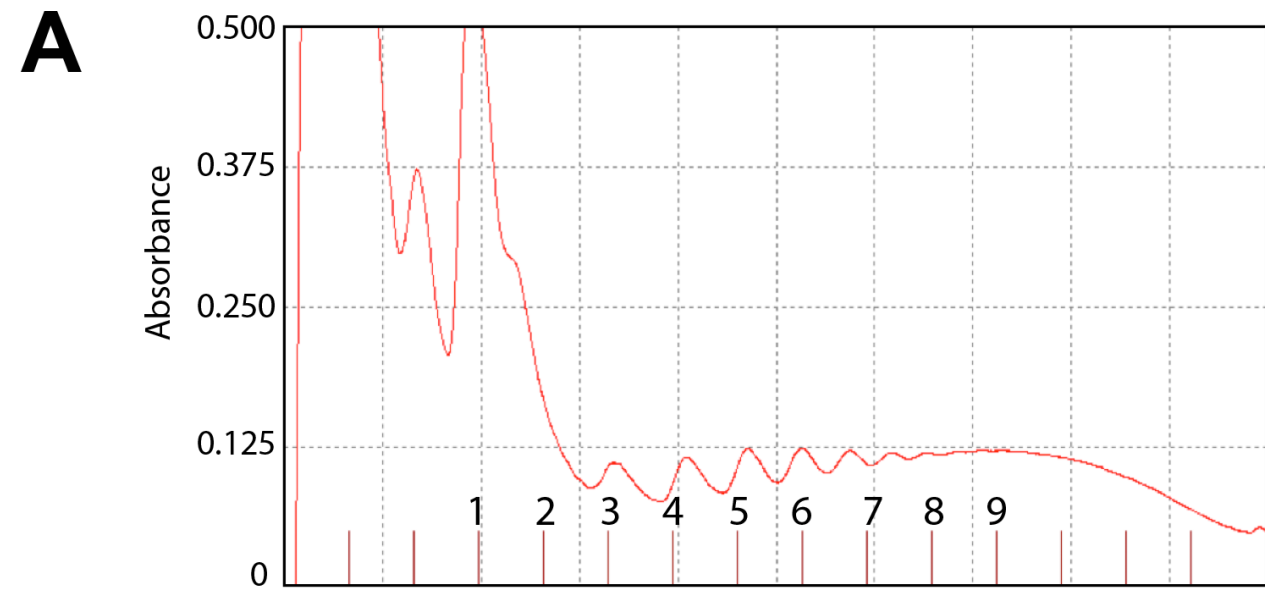

B

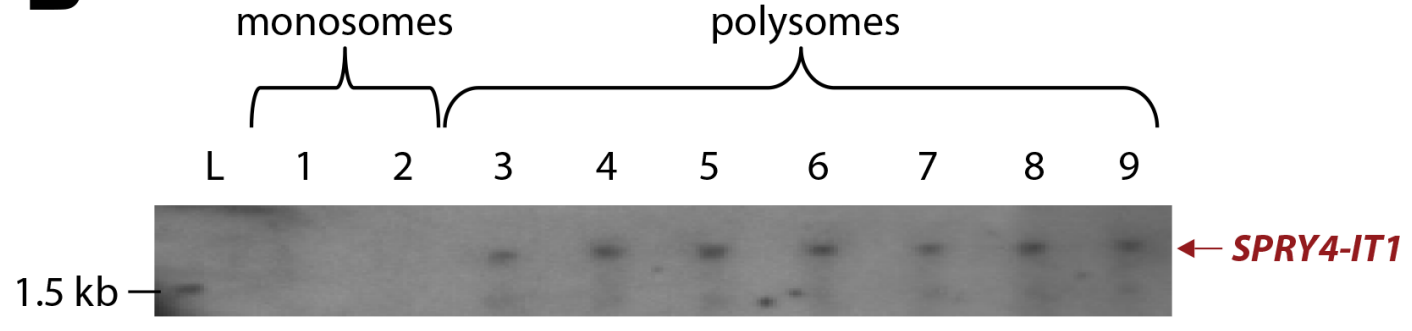

$1.5 \mathrm{~kb}$

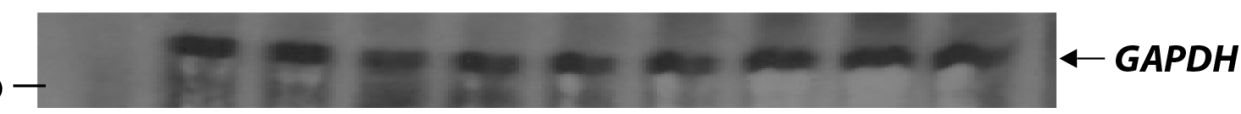

Figure 3: SPRY4-IT1 Accumulates in Polysomes and Is Absent from Monosomes. (A) Density gradient fractionation of monosome and polysome peaks. (B) Northern blot analysis showing SPRY4-IT1 probe hybridization to RNA isolated from polysomes but not monosomes. A GAPDH probe served as a control. Separate blots were prepared to probe SPRY4-IT1 and control (GAPDH) due to concerns of overlap in fragment size. $\mathrm{L}=$ RNA size marker. 
including increased acyl carnitines $(+80.21 \%)$, fatty acyl chains $(+14.24 \%)$, and triacylglycerol (TAG) $(+15.02 \%)$, as well as decreased phosphatidic acid (-37.72\%), phosphatidylcholine $(-35.58 \%)$, phosphatidylinositol $(-27.78 \%)$, and phosphatidylserine (-26.40\%). Interestingly, DAG content was decreased despite the increase in TAG levels. Since DAG is required for TAG synthesis, we hypothesized that the reduction in DAG levels in SPRY4-IT1 knockdown cells may be due to efficient conversion of DAG to TAG. To test this, we examined the expression of acyl-CoA:glycerol-3phosphate acyltransferase 3 (GPAT3), diacylglycerol
O-acyltransferase 1 (DGAT1), and diacylglycerol O-acyltransferase 2 (DGAT2), since these enzymes play essential roles in DAG to TAG conversion. qPCR analysis showed that both DGAT2 and GPAT3 mRNA levels were increased in SPRY4-IT1 knockdown cells (Fig. 5), providing a possible mechanism for the changes in DAG and TAG levels in these cells. We postulate that one mechanism by which SPRY4-IT1 knockdown induces apoptosis could be through lipin 2-mediated lipotoxicity. To investigate further, we knocked-down and overexpressed lipin 2 in A375 cells and measured cell invasion efficiency and doubling time. Interestingly, we observed

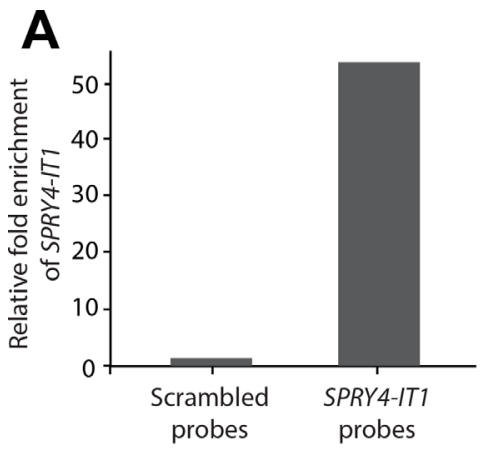

\section{C}
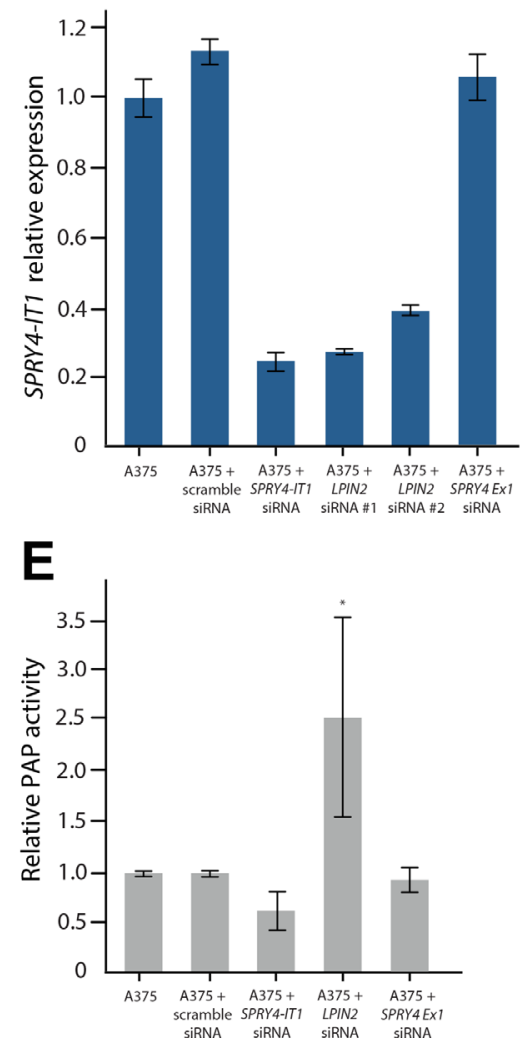

B

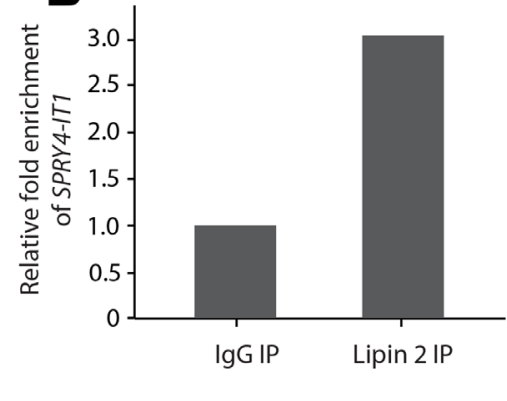

D

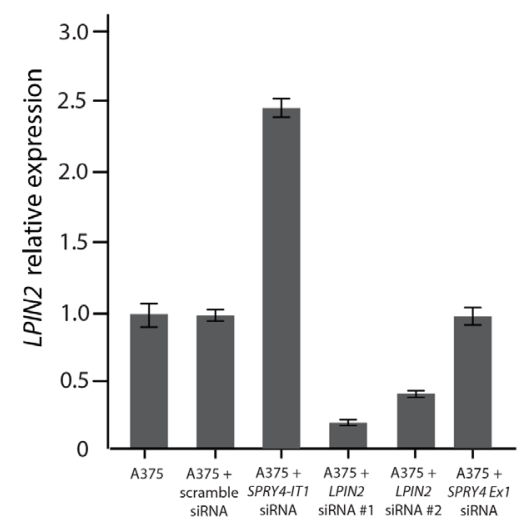

$\mathbf{F}$

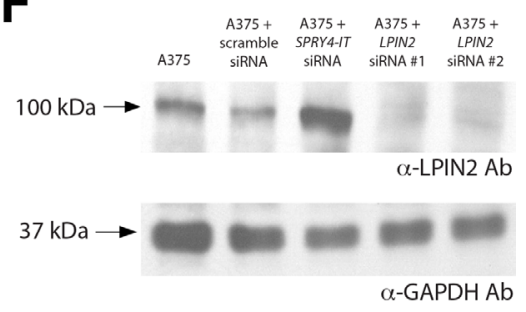

Figure 4:SPRY4-IT1 Knockdown Increases Lipin 2 Protein Accumulation in Melanoma Cells. A) Affinity purification of SPRY4-IT1 from A375 cell lysates with SPRY4-IT1-specific probes followed by qPCR. SPRY4-IT1 is enriched compared to scrambled (control) probes. U1 RNA was used as endogenous control for pull-downs. (B) qPCR validation showing enrichment of SPRY4-IT1 following immunoprecipitation of A375 cell lysates with lipin 2-specific or control IgG antibodies. (C) Relative expression of SPRY4-IT1 in lipin 2 knock-down cells (D) Relative expression of lipin 2 after siRNA-mediated knockdown of SPRY4-IT1, SPRY4 exon 1 or lipin 2. (E) Phosphatidic acid phosphatase assay. (F) Western blot analysis of lipin 2 following siRNA-mediated knockdown of SPRY4-IT1 or lipin 2. All experiments were performed in triplicate. 
that cell doubling time was increased and cell invasion was decreased in both knock-down and force-expressed cells (Fig. S6A and B). We postulate that lipin 2 levels must be maintained on a steady state level in melanoma cells, and modulating lipin 2 levels (either an increase or decrease) can negatively affect cell physiology. For comparison, we subjected the primary melanocyte cell line HEM-1 to shotgun lipidomics, and compared cellular lipid profiles to A375 cells. Interestingly, we found that lipid levels were significantly different in these two cell types. For an example, phosphatidylethanolamine (PE), Phosphatidylserine (PS), Phosphatidic acid (PA), Sphingomyelin (SM) were higher in melanocytes, compared to melanoma cells (Table S3). Studying the role of lipids in melanocyte and melanoma biology is an ongoing study in our laboratory.

\section{DISCUSSION}

In contrast to small ncRNAs, which are highly conserved and play a role in transcriptional and posttranscriptional gene silencing through specific base pairing, lncRNAs are often poorly conserved (perhaps reflecting lineage specificity and/or more plastic structurefunction constraints) and regulate gene expression by diverse mechanisms that are not yet fully understood. We previously identified the lncRNA SPRY4-IT1, which is derived from the intronic region of the Sprouty 4 gene, and is upregulated in human melanomas compared to normal melanocytes and keratinocytes [14]. siRNA-mediated knockdown of SPRY4-IT1 in melanoma was shown to affect cell proliferation and apoptosis, suggesting that high SPRY4-IT1 expression may play an important role in the molecular etiology of human melanomas. In this study, we sought to probe this further by identifying the A
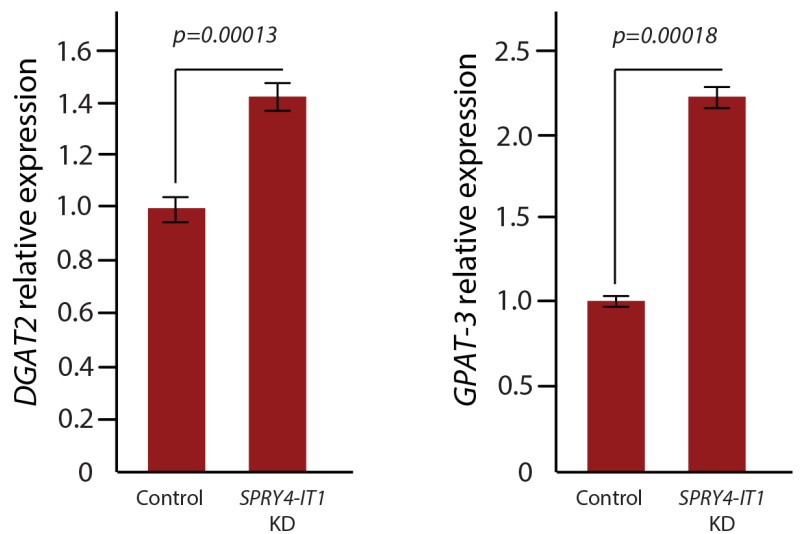

Figure 5: Expression of Diacylglycerol O-acyltransferase 2 and (DGAT2) Acyl-coA:glycerol3-phosphate Acyltransferase 3 (GPAT3) Following SPRY4-IT1 Knockdown. Both DGAT2 (A) and GPAT3 (B) mRNA levels are increased upon knockdown of SPRY4-IT1 in A375 cells, which may explain the decrease in DAG levels and increase in TAG levels observed in these cells (Table S2). molecular function of SPRY4-IT1 and elucidating its possible molecular function in melanomas.

We found that SPRY4-IT1 is part of a longer noncoding transcript that is processed by cleavage of a $244 \mathrm{nt} 5^{\prime}$ fragment prior to transport to the cytoplasm. The fate of the $244 \mathrm{nt}$ fragment is unknown, but it is likely to be degraded by exo- and endonucleases. The maturation of SPRY4-IT1 is similar to the nuclear processing of $M A L A T 1$ in lung cancer [30]. We also showed that SPRY4 and SPRY4-IT1 are independent transcripts, although they may be regulated by the same transcriptional machinery. A recent study classifying lncRNAs according to their genomic origin showed they may originate from (a) a bidirectional promoter adjacent to a protein-coding gene, (b) the 5' UTR, (c) a retained intron, (d) within an intron, (e) the $3^{\prime}$ UTR, (f) an intergenic non-proteincoding region, (g) antisense to protein-coding genes, or (f) a combination of the above [31]. According to this classification, SPRY4-IT1 therefore belongs to the group of intron-retained lncRNAs.

One of the direct targets of SPRY4-IT1 identified in this study is lipin 2, a member of the lipin family of phosphatidate phosphatase enzymes [32]. The mouse lipin 2 protein has previously been shown to be post-transcriptionally regulated [33]. We showed that knockdown of SPRY4-IT1 modulates cellular concentrations of lipin 2 substrates, including phosphatidate, and cells expressing high SPRY4-IT1 levels, such as melanomas, might thus be expected to accumulate lipin 2 substrates. Indeed, increased levels of phosphatidate have been linked to certain types of cancers through allosteric activation of the molecular target of rapamycin (mTOR) [34] and to a possible role for lipin 2 in statin resistance of colorectal carcinoma cells in vitro [35]. It would be of interest to determine whether the influence of SPRY4-IT1 on melanocyte and melanoma proliferation involves inhibition of lipin 2 activity and/or activation of mTOR.

Our results are the first to demonstrate a role for a lncRNA in lipid metabolism in melanoma cells, and collectively, the data support the notion that SPRY4-IT1 may play a critical role in melanocytic transformation.

\section{MATERIAL AND METHODS}

\section{Cell Lines}

Human epidermal melanocytes (HEM-1) were grown in MelM media containing MelGS growth supplements, $0.5 \%$ fetal bovine serum (FBS), penicillin, and streptomycin. Melanoma cells A375 (stage 4) were grown in Complete Tu medium containing a 4:1 mixture of MCDB-153 medium with $1.5 \mathrm{mg} / \mathrm{ml}$ sodium bicarbonate and Leibovitz's L-15 medium with $2 \mathrm{mM}$ L-glutamine, 
$2 \% \mathrm{FBS}$, and $1.68 \mathrm{mM} \mathrm{CaCl} 2$. Cells were grown at $37^{\circ} \mathrm{C}$ in a humidified $5 \% \mathrm{CO} 2$ atmosphere. All cell lines were obtained from ATCC (http://www.atcc.org).

\section{Cloning and Identification of 3' Spliced Forms of SPRY4-IT1}

Total RNA was isolated from A375 cells with TRIzol (Invitrogen) and reversed transcribed using M-MLV reverse transcriptase. The cDNA was used as a template for PCR amplification with various $5^{\prime}$ primers within SPRY4-IT1 and 3' primers downstream in the SPRY4 locus. Successful amplification was achieved with two forward primers: 5' IT1 (gtagagatgggggtttcatcctgttg), which anneals to the first base of SPRY4-IT1, and SPRY4IT1 qPCR (gctgagctggtggttgaaaggaatc), which is located $305 \mathrm{bp}$ within the SPRY4-IT1 sequence. Successful amplification at the 3' end was achieved with the reverse primer SPRY4 Exon 3 (gtccgctttgggecggtgg), which is located 229 bp into the third exon of SPRY4. Amplification was unsuccessful using primers $500 \mathrm{bp}$ downstream of this location. PCR products were cloned and sequenced. Sequences were aligned to the genomic template and verified using Vector NTi Advance and AlignX.

\section{Northern Blot Analysis}

Total RNA was isolated from each cell line with TRIzol and concentrated. Aliquots of RNA (20 $\mu \mathrm{g}$ per sample) were mixed with equal volumes of $2 \times$ NorthernMax-Gly Loading Dye (with ethidium bromide), heated at $50^{\circ} \mathrm{C}$ for $30 \mathrm{~min}$, and resolved on a $1 \%$ glyoxal agarose gel run at $65 \mathrm{~V}$ for $2 \mathrm{~h} 20 \mathrm{~min}$ in $1 \times$ running buffer. The gel was transferred to a nylon membrane (BrightStar Plus, Ambion) using downward capillary transfer, crosslinked using a UVP UV crosslinker at 1200 (UVP HL-2000 HybriLinker), prehybridized for $30 \mathrm{~min}$ at $42^{\circ} \mathrm{C}$ in $6 \mathrm{ml}$ ULTRAhyb (Ambion), and then probed overnight at $42^{\circ} \mathrm{C}$. Blots were processed with the BrightStar BioDetect kit (Ambion) and exposed to film. The following biotin-labeled DNA probes (IDT) were used at $166 \mathrm{nM}$ : SPRY4-ITI, ctccactgggcatattctaaaa; SPRY4 Exon 1, gatgttgcaaccactgcctgg; SPRY4 Exon 3, catggctggtcttcacctggtc; and GAPDH, gggccatgaggtccaccaccc.

\section{Invasion Assay}

A375 cells were trypsinized and reverse transfected using RNAiMax (Life Technologies) with $50 \mu \mathrm{M}$ of the following siRNAs (Life Technologies): SPRY4-ITI Stealth RNAi 594, SPRY4 Exon 1 Custom Select siRNA, lipin 2 Silencer Select siRNAs s18590 and s18591, and Universal Negative control (Cat \#46-2001).
BD BioCoat ${ }^{\mathrm{TM}}$ Matrigel ${ }^{\mathrm{TM}}$ Invasion Chambers (24-well plates) were prepared by rehydrating the BD Matrigel ${ }^{\mathrm{TM}}$ matrix coating with $0.5 \mathrm{ml}$ of serumfree Complete $\mathrm{Tu}$ medium for $2 \mathrm{~h}$ at $37^{\circ} \mathrm{C}$ in a $5 \%$ $\mathrm{CO}_{2}$ atmosphere. After rehydration, the solution was removed and $0.5 \mathrm{ml}$ of Complete Tu medium containing chemoattractant ( $2 \%$ FBS) was added to the lower wells, and $0.5 \mathrm{ml}$ of serum-free Complete Tu medium containing $5 \times 10^{4}$ A375 cells transfected with siRNAs was added to the insert wells. Invasion assay plates were incubated for 2 days at $37^{\circ} \mathrm{C}$ in a humidified $5 \% \mathrm{CO}_{2}$ atmosphere. Non-invading cells were removed by scrubbing the upper surface of the insert, and invading cells on the lower surface of the insert were stained with crystal violet. Each membrane was mounted on a microscope slide for visualization and analysis. Slides were scanned using a Scanscope digital slide scanner, and the migrated cells were enumerated using Aperio software. All experiments were performed with biological triplicates.

\section{Apoptosis Assay}

A375 cells were trypsinized and reverse transfected with siRNAs as described above. Caspase activity was measured using the Caspase-Glo@ 3/7 Assay kit (Promega) according to the manufacturer's recommendations, and samples were read on a GloMax luminometer (Promega).

\section{Polysome Fractionation}

Cells grown in $10 \mathrm{~cm}$ dishes were gently removed with PBS and collected by centrifugation for $4 \mathrm{~min}$ at 100 $\times \mathrm{g}$. The cell pellet was resuspended in $500 \mu \mathrm{l}$ of lysis buffer $(100 \mathrm{mM} \mathrm{KCl}, 50 \mathrm{mM}$ Tris- $\mathrm{HCl} \mathrm{pH}$ 7.4, $1.5 \mathrm{mM}$ $\mathrm{MgCl}_{2}, 1 \mathrm{mM}$ dithiothreitol (DTT), $1 \mathrm{mg} / \mathrm{ml}$ heparin, $1.5 \% \mathrm{NP}-40,100 \mu \mathrm{M}$ cycloheximide, $1 \%$ aprotinin, $1 \mathrm{mM}$ AEBSF, and $100 \mathrm{U} / \mathrm{ml}$ of RNasin) and incubated on ice for $15 \mathrm{~min}$. The lysate was centrifuged at $1000 \times \mathrm{g}$ and the infranatant lysate was removed from underneath the "fat cake". The nuclei were pelleted by centrifugation in a microfuge for $10 \mathrm{~min}$ at $12,000 \mathrm{rpm}$. The resulting supernatant was carefully removed and applied to the top of a $15-60 \%$ sucrose gradient (in $100 \mathrm{mM} \mathrm{KCl}, 5 \mathrm{mM}$ $\mathrm{MgCl}_{2}, 20 \mathrm{mM}$ HEPES $\mathrm{pH} 7.4$, and $2 \mathrm{mM}$ DTT). The gradients were centrifuged at $35,000 \mathrm{rpm}$ for $3.5 \mathrm{~h}$ at $4{ }^{\circ} \mathrm{C}$ in a Beckman SW41 rotor. Samples containing (i) free (unbound) mRNA, ribosomal subunits, and monosomes, and (ii) polysomes were recovered from the gradients using a Brandel density gradient fractionator equipped with an ISCO UA-6 flow cell set to $254 \mathrm{~nm}$ (a 70\% sucrose solution containing orange $\mathrm{G}$ was slowly pumped into the bottom of the tube to displace the contents from top to bottom). Fractions were collected directly into an equal volume of TRIzol for isolation of RNA. The purity and integrity of RNA was determined with an Agilent 
Bioanalyzer prior to analysis by northern blotting.

\section{Affinity Purification of Endogenous SPRY4-IT1}

A375 cells $\left(10^{8}\right.$ per sample) were grown to 80 $90 \%$ confluency, the medium was discarded, and the plates were washed with PBS. The cells were trypsinized, pelleted at low speed, washed with PBS, and resuspended in $90 \mathrm{ml}$ PBS $\left(\sim 10^{6}\right.$ cells $\left./ \mathrm{ml}\right)$. Cells were crosslinked by incubation in $1 \%$ formaldehyde at RT with rotation, and then quenched by the addition of glycine to a final concentration of $375 \mathrm{mM}$ for $5 \mathrm{~min}$. The cells were centrifuged at low speed, washed in PBS, and recentrifuged. The pellet was resuspended in Buffer A (1\% NP-40, 1 mM DTT), homogenized, and spun at low speed. The pellet was resuspended in nuclei lysis buffer ( $1 \mathrm{mM}$ DTT, $1 \times$ protease inhibitor, and $2 \mu \mathrm{l}$ RaseOut) at a volume of $1 \mathrm{ml}$ per $25 \times 10^{6}$ cell equivalents. The lysate was incubated on ice, sonicated to yield 100-500 bp fragments (Duty Cycle, 20\%; intensity, 10; cycles/burst, 200; and time, $8 \mathrm{~min}$ ), and then centrifuged at high speed. The supernatant was removed and mixed with $0.5 \mathrm{M}$ $\mathrm{LiCl}_{2}$, then $500 \mathrm{pmol} / 25 \times 10^{6}$ cell equivalents of a SPRY4IT1 probe was added, and the sample was incubated at $37^{\circ} \mathrm{C}$ for $24 \mathrm{~h}$. The probe consisted of a 25 -bp sequence complementary to SPRY4-IT1 constructed with a locked nucleic acid (LNA) backbone and a 5'-biotin label. Control samples contained probes complementary to the test probe sequence. A $2 \mathrm{ml}$ aliquot of streptavidin-coated Dynabeads (Life Technologies) was washed twice with water and once with hybridization buffer, and then blocked with 800 $\mu \mathrm{g}$ yeast tRNA and $800 \mu \mathrm{g}$ BSA for $1 \mathrm{~h}$ at $37^{\circ} \mathrm{C}$. The beads were pelleted, washed twice in nuclear lysis buffer, and resuspended in $2 \mathrm{ml}$ of the same buffer. Prepared beads were added to the nuclear lysate $(125 \mu \mathrm{l}$ per $500 \mathrm{pmol}$ of probe), rotated at $37^{\circ} \mathrm{C}$, and then washed twice in $1 \mathrm{ml}$ nuclear lysis buffer and twice in $1 \mathrm{ml}$ wash buffer $(5 \mathrm{mM}$ Tris- $\mathrm{HCl} \mathrm{pH}$ 7.5, $0.5 \mathrm{mM}$ EDTA, $1 \mathrm{M} \mathrm{NaCl}$ ). Beads from replicate samples were combined, washed twice in PBS, resuspended in $\mathrm{PBS}$, incubated at $75^{\circ} \mathrm{C}$ for $5 \mathrm{~min}$, and applied to a magnet. The isolated beads were incubated at $65^{\circ} \mathrm{C}$ overnight to reverse crosslinking, treated with $1 \mu \mathrm{g} /$ $\mathrm{ml}$ RNase A, vortexed, and incubated at RT. The samples were then treated with proteinase $\mathrm{K}$, resuspended in Buffer $\mathrm{AL}$, and incubated at $56^{\circ} \mathrm{C}$. Finally, RNA in the complexes was purified using the DNeasy Kit, eluted in RNase-free $\mathrm{H}_{2} \mathrm{O}$, and qRT-PCR was performed to quantify SPRY4-IT1. The RNA-protein complexes were then subjected to LTQ Orbitrap Velos MS for analysis of SPRY4-IT1-associated proteins. Protein digestion, $\mathrm{TiO}_{2}$-based phosphopeptide enrichment, and ESI-MS/MS was performed at the proteomics core facility at Sanford-Burnham. Table S1 lists the identified SPRY4-IT1-binding proteins. RNA coimmunoprecipitation (RIP) was performed as previously described [36]. Lipin-2 antibody H-160 was from Santa Cruz (sc-134433).

\section{Real-time qRT-PCR}

Quantitative PCR was carried out using TaqMan mRNA or SYBR Green mRNA assays with a 7500 Real-Time PCR System (Applied Biosystems/Life Technologies), in accordance with the manufacturer's protocols. SDS1.2.3 software (Applied Biosystems) was used for comparative $\mathrm{Ct}$ analysis, with $18 \mathrm{~S}$ rRNA serving as the endogenous control. Primers for SYBR qPCR were as follows: SPRY4-IT1 qPCR For, gctgagctggtggttgaaaggaatc; SPRY4-IT1 qPCR Rev, gettggcccacgatgacttgg; SPRY4 Exon 1 qPCR For, ggcagtggttgcaacatcgecg; SPRY4 Exon 1 qPCR Rev, tagccgcegctgtactcgcagac; LPIN2 qPCR For, cgtctaagcagccettctatgctgc; LPIN2 qPCR Rev, acatgctccacgagctcactcagc; LPIN1 qPCR For, ggagagctggtacaggaacatgcaaag; LPIN1 qPCR Rev, gcagtggctctctccaaaaggtgaag; GPAT3 qPCR For, caaggaggcetgactgaacttcc;; GPAT3 qPCR Rev, ccgtcctcttagctgagagatccattg; DGAT1 qPCR For, caacaaggacggagacgccgg; DGAT1 qPCR Rev, gatgccacggtagttgetgaagcc; DGAT2 qPCR For, ctgcactgattgctggctcatcg; and DGAT2 qPCR Rev, gaaagtagcgccacacagcccag.

\section{RNA-FISH Analysis}

RNA-FISH was performed using an LNAmodified probe for human SPRY4-IT1 (5'-Texas RedTCCACTGGGCATATTCTAAAA) and a RiboMap in situ hybridization kit (Ventana Medical Systems, Inc.) on a Ventana machine. SPRY4-IT1-EE and vector-only cells were resuspended at $10^{5}$ cells $/ \mathrm{ml}$, and $100 \mu \mathrm{l}$ was added to separate cloning rings on an autoclaved glass slide. The following day, the rings were removed, and the slide was washed in PBS and fixed in 4\% paraformaldehyde and $5 \%$ acetic acid. After acid treatment using hydrochloridebased RiboClear reagent (Ventana Medical Systems) for $10 \mathrm{~min}$ at $37^{\circ} \mathrm{C}$, the slide was treated with the ready-touse protease 3 reagent, and subjected to a denaturing prehybridization step for $4 \mathrm{~min}$ at $80^{\circ} \mathrm{C}$. The cells were then hybridized with 40 nM LNA-modified probe in RiboHybe hybridization buffer (Ventana Medical Systems) for $2 \mathrm{~h}$ at $58^{\circ} \mathrm{C}$. The slide was washed 3 times for $4 \mathrm{~min}$ at $60^{\circ} \mathrm{C}$; once at low stringency with $0.1 \times$ SSC (Ventana Medical Systems) and twice with $1 \times$ SSC. The slides were fixed in RiboFix and counterstained with DAPI in an antifade reagent (Ventana Medical Systems). Images were acquired using a Nikon A1R VAAS laser confocal microscope.

\section{5' RACE for SPRY4-IT1}

5' RACE was performed using the FirstChoice ${ }^{\circledR}$ RLM-RACE (RNA Ligase-Mediated RACE) kit 
(Ambion, Life Technologies). Total RNA was isolated from A375 cells with TRIzol, and $1 \mu \mathrm{g}$ per sample was ligated to the 5' RACE adapter using T4 RNA Ligase. This sample was then reverse transcribed using M-MLV reverse transcriptase. The samples were not treated with either calf intestinal alkaline phosphatase or tobacco acid pyrophosphatase and mRNA molecules thus retained both the 5' 7-methyl cap and the 5' phosphate. Multiple reverse primers were designed within the SPRY4-IT1 sequence to complement the forward 5' RLM-RACE primers. PCR reactions were performed using Phusion polymerase (Finnzymes), run out and purified from agarose gels, and cloned into pCR4-TOPO (Life Technologies) for sequence evaluation (Retrogen). The SPRY4-IT1 RACE product was successfully acquired using the 5' RACE inner primer (supplied with the FirstChoice ${ }^{\circledR}$ kit) and $5^{\prime}$ RACE SPRY4-IT1 reverse primer, residing 385 bp into SPRY4IT1 (ctctctggggacgatgcagcatccgatgg).

\section{ACKNOWLEDGMENTS}

We thank Drs. Ze'ev Ronai and Fred Levin (both from SBMRI) for their valuable comments and suggestions to improve the manuscript. We also thank Drs. Marc Beal and Arturo Orjalo (both from Biosearch) for Stellaris RNA-FISH probes, Dr. Susan Magdaleno (Life Technologies) for siRNA reagents, Debbie McFadden (SBMRI) for formatting the manuscript, and Dr. Anne O'Rourke for editorial assistance. This work was supported by National Institutes of Health grants CA165184 and NCI 5P30CA030199 and an Oakstone Foundation grant to RJP and DK078187 to BNF. MED and JSM are supported by a Career Development Award and an Australia Fellowship, respectively, from the National Health and Medical Research Council of Australia. The authors have no conflicts of interest to declare.

\section{REFERENCES}

1. Carninci P, Kasukawa T, Katayama S, Gough J, Frith MC, Maeda N, Oyama R, Ravasi T, Lenhard B, Wells C, Kodzius R, Shimokawa K, Bajic VB, Brenner SE, Batalov $\mathrm{S}$, Forrest AR, et al. The transcriptional landscape of the mammalian genome. Science. 2005; 309(5740):1559-1563.

2. Cheng J, Kapranov P, Drenkow J, Dike S, Brubaker S, Patel S, Long J, Stern D, Tammana H, Helt G, Sementchenko V, Piccolboni A, Bekiranov S, Bailey DK, Ganesh M, Ghosh $\mathrm{S}$, et al. Transcriptional maps of 10 human chromosomes at 5-nucleotide resolution. Science. 2005; 308(5725):11491154 .

3. Mercer TR, Dinger ME and Mattick JS. Long non-coding RNAs: insights into functions. Nat Rev Genet. 2009; 10(3):155-159.

4. Moran VA, Perera RJ and Khalil AM. Emerging functional and mechanistic paradigms of mammalian long non-coding
RNAs. Nucleic Acids Res. 2012; 40(14):6391-6400.

5. Mattick JS, Amaral PP, Dinger ME, Mercer TR and Mehler MF. RNA regulation of epigenetic processes. Bioessays. 2009; 31(1):51-59.

6. Mercer TR and Mattick JS. Structure and function of long noncoding RNAs in epigenetic regulation. Nat Struct Mol Biol. 2013; 20(3):300-307.

7. Banfai B, Jia H, Khatun J, Wood E, Risk B, Gundling WE, Jr., Kundaje A, Gunawardena HP, Yu Y, Xie L, Krajewski K, Strahl BD, Chen X, Bickel P, Giddings MC, Brown JB, et al. Long noncoding RNAs are rarely translated in two human cell lines. Genome research. 2012; 22(9):1646-1657.

8. Gascoigne DK, Cheetham SW, Cattenoz PB, Clark MB, Amaral PP, Taft RJ, Wilhelm D, Dinger ME and Mattick JS. Pinstripe: a suite of programs for integrating transcriptomic and proteomic datasets identifies novel proteins and improves differentiation of protein-coding and non-coding genes. Bioinformatics. 2012; 28(23):3042-3050.

9. Clark MB, Amaral PP, Schlesinger FJ, Dinger ME, Taft RJ, Rinn JL, Ponting CP, Stadler PF, Morris KV, Morillon A, Rozowsky JS, Gerstein MB, Wahlestedt C, Hayashizaki Y, Carninci P, Gingeras TR, et al. The reality of pervasive transcription. PLoS Biol. 2011; 9(7):e1000625; discussion e1001102.

10. Taft RJ, Pang KC, Mercer TR, Dinger M and Mattick JS. Non-coding RNAs: regulators of disease. J Pathol. 2010; 220(2):126-139.

11. Amaral PP and Mattick JS. Noncoding RNA in development. Mamm Genome. 2008; 19(7-8):454-492.

12. Mercer TR, Dinger ME, Sunkin SM, Mehler MF and Mattick JS. Specific expression of long noncoding RNAs in the mouse brain. Proceedings of the National Academy of Sciences of the United States of America. 2008; 105(2):716721.

13. Sunwoo H, Dinger ME, Wilusz JE, Amaral PP, Mattick JS and Spector DL. MEN varepsilon/beta nuclear-retained noncoding RNAs are up-regulated upon muscle differentiation and are essential components of paraspeckles. Genome research. 2009; 19(3):347-359.

14. Khaitan D, Dinger ME, Mazar J, Crawford J, Smith MA, Mattick JS and Perera RJ. The melanoma-upregulated long noncoding RNA SPRY4-IT1 modulates apoptosis and invasion. Cancer Res. 2011; 71(11):3852-3862.

15. Pandey RR, Mondal T, Mohammad F, Enroth S, Redrup L, Komorowski J, Nagano T, Mancini-Dinardo D and Kanduri C. Kcnq1ot1 antisense noncoding RNA mediates lineagespecific transcriptional silencing through chromatin-level regulation. Mol Cell. 2008; 32(2):232-246.

16. Umlauf D, Fraser P and Nagano T. The role of long noncoding RNAs in chromatin structure and gene regulation: variations on a theme. Biol Chem. 2008; 389(4):323-331.

17. Rinn JL and Chang HY. Genome regulation by long noncoding RNAs. Annu Rev Biochem. 2012; 81:145-166.

18. Dinger ME, Amaral PP, Mercer TR, Pang KC, Bruce SJ, 
Gardiner BB, Askarian-Amiri ME, Ru K, Solda G, Simons C, Sunkin SM, Crowe ML, Grimmond SM, Perkins AC and Mattick JS. Long noncoding RNAs in mouse embryonic stem cell pluripotency and differentiation. Genome Res. 2008; 18(9):1433-1445.

19. Khalil AM, Guttman M, Huarte M, Garber M, Raj A, Rivea Morales D, Thomas K, Presser A, Bernstein BE, van Oudenaarden A, Regev A, Lander ES and Rinn JL. Many human large intergenic noncoding RNAs associate with chromatin-modifying complexes and affect gene expression. Proc Natl Acad Sci U S A. 2009; 106(28):11667-11672.

20. Tsai MC, Manor O, Wan Y, Mosammaparast N, Wang JK, Lan F, Shi Y, Segal E and Chang HY. Long noncoding RNA as modular scaffold of histone modification complexes. Science. 2010; 329(5992):689-693.

21. Dinger ME, Amaral PP, Mercer TR, Pang KC, Bruce SJ, Gardiner BB, Askarian-Amiri ME, Ru K, Solda G, Simons C, Sunkin SM, Crowe ML, Grimmond SM, Perkins AC and Mattick JS. Long noncoding RNAs in mouse embryonic stem cell pluripotency and differentiation. Genome research. 2008; 18(9):1433-1445.

22. Esteller M. Non-coding RNAs in human disease. Nat Rev Genet. 2011; 12(12):861-874.

23. Kim K, Jutooru I, Chadalapaka G, Johnson G, Frank J, Burghardt R, Kim S and Safe S. HOTAIR is a negative prognostic factor and exhibits pro-oncogenic activity in pancreatic cancer. Oncogene. 2012.

24. Ifere GO and Ananaba GA. Prostate cancer gene expression marker 1 (PCGEM1): a patented prostate- specific noncoding gene and regulator of prostate cancer progression. Recent Pat DNA Gene Seq. 2009; 3(3):151-163.

25. Mazar J, Sinha S, Dinger ME, Mattick JS and Perera RJ. Protein-coding and non-coding gene expression analysis in differentiating human keratinocytes using a threedimensional epidermal equivalent. Mol Genet Genomics. 2010; 284(1):1-9.

26. Ota T, Suzuki Y, Nishikawa T, Otsuki T, Sugiyama T, Irie R, Wakamatsu A, Hayashi K, Sato H, Nagai K, Kimura K, Makita H, Sekine M, Obayashi M, Nishi T, Shibahara T, et al. Complete sequencing and characterization of 21,243 full-length human cDNAs. Nat Genet. 2004; 36(1):40-45.

27. Minowada G, Jarvis LA, Chi CL, Neubuser A, Sun X, Hacohen N, Krasnow MA and Martin GR. Vertebrate Sprouty genes are induced by FGF signaling and can cause chondrodysplasia when overexpressed. Development. 1999; 126(20):4465-4475.

28. Ingolia NT, Brar GA, Rouskin S, McGeachy AM and Weissman JS. The ribosome profiling strategy for monitoring translation in vivo by deep sequencing of ribosome-protected mRNA fragments. Nature protocols. 2012; 7(8):1534-1550.

29. Gropler MC, Harris TE, Hall AM, Wolins NE, Gross RW, Han X, Chen Z and Finck BN. Lipin 2 is a liverenriched phosphatidate phosphohydrolase enzyme that is dynamically regulated by fasting and obesity in mice. The Journal of biological chemistry. 2009; 284(11):6763-6772.

30. Wilusz JE, Freier SM and Spector DL. 3' end processing of a long nuclear-retained noncoding RNA yields a tRNA-like cytoplasmic RNA. Cell. 2008; 135(5):919-932.

31. Khachane AN and Harrison PM. Mining mammalian transcript data for functional long non-coding RNAs. PLoS One. 2010; 5(4):e10316.

32. Harris TE and Finck BN. Dual function lipin proteins and glycerolipid metabolism. Trends in endocrinology and metabolism: TEM. 2011; 22(6):226-233.

33. Gropler MC, Harris TE, Hall AM, Wolins NE, Gross RW, Han X, Chen Z and Finck BN. Lipin 2 is a liverenriched phosphatidate phosphohydrolase enzyme that is dynamically regulated by fasting and obesity in mice. J Biol Chem. 2009; 284(11):6763-6772.

34. Foster DA. Regulation of mTOR by phosphatidic acid? Cancer Res. 2007; 67(1):1-4.

35. Savas S, Azorsa DO, Jarjanazi H, Ibrahim-Zada I, Gonzales IM, Arora S, Henderson MC, Choi YH, Briollais L, Ozcelik $\mathrm{H}$ and Tuzmen S. NCI60 cancer cell line panel data and RNAi analysis help identify EAF2 as a modulator of simvastatin and lovastatin response in HCT-116 cells. PLoS One. 2011; 6(4):e18306.

36. Moran VA, Niland $\mathrm{CN}$ and Khalil AM. CoImmunoprecipitation of long noncoding RNAs. Methods Mol Biol. 2012; 925:219-228. 